\title{
Programming of Adult Cardiovascular Disease following Exposure to Late-Gestation Hyperglycemia
}

\author{
Melissa Agoudemos Benjamin E. Reinking Stacia L. Koppenhafer \\ Jeffrey L. Segar Thomas D. Scholz \\ Departments of Pediatrics, University of lowa, lowa City, lowa, USA
}

\section{Key Words \\ Fetal programming $\cdot$ Developmental programming $\cdot$ Infant of diabetic mother - Diabetes - Myocardium . \\ Diastolic dysfunction - Echocardiography}

\begin{abstract}
Background: In utero exposure to hyperglycemia is becoming increasingly prevalent as the number of women entering pregnancy with type II diabetes, or developing gestational diabetes, increases. Both animal studies and epidemiologic investigations have found cardiovascular abnormalities in adult offspring of hyperglycemic mothers (OHM). Objective: We hypothesized that adult OHM would have abnormal cardiac function in vivo and increased susceptibility to ischemia. Methods: Pregnant rats were made diabetic on day 12 of gestation. Serum glucose was monitored twice daily and insulin provided to maintain serum glucose at 200-400 $\mathrm{mg} / \mathrm{dl}$. Offspring were fostered to normal mothers after birth. Adult OHM were studied at 8-10 months of age with echocardiography to assess in vivo cardiac function and isolated hearts to determine the response to ischemia. Results: Echocardiography found significant diastolic dysfunction in male OHM compared to male controls. In isolated hearts, baseline cardiac function and left ventricular compliance was significantly diminished in male OHM compared to controls. Ischemia caused a significant decline in heart function
\end{abstract}

in controls and female OHM, while function in male OHM remained unchanged. Conclusions: Adult male OHM demonstrate programmed cardiac dysfunction. Given the growing number of pregnancies complicated by hyperglycemia, additional assessment of cardiac function of adults born to diabetic mothers may be warranted.

Copyright $\odot 2011$ S. Karger AG, Basel

\section{Introduction}

Maternal hyperglycemia results in an adverse intrauterine environment for the developing fetus. There is growing evidence that exposure to hyperglycemia in utero not only has short-term consequences, but long-term sequelae which include cardiovascular disease and metabolic syndrome [1-3]. This is consistent with the concept of fetal or developmental programming initially described by Barker et al. $[4,5]$ whereby the intrauterine environment impacts the adult phenotype.

Defining the long-term effects of in utero hyperglycemia exposure and their mechanisms has significant public health implications. The ongoing obesity epidemic is resulting in an increasing number of pregnancies in whom mothers are entering pregnancy with glucose intolerance or developing gestational diabetes. The past 8 years has seen more than a doubling in the number of

\section{KARGER}

(C) 2011 S. Karger AG, Basel

Fax +41613061234 E-Mail karger@karger.ch www.karger.com
Accessible online at: www.karger.com/neo
Thomas D. Scholz, MD

Division of Pediatric Cardiology, 2801 JPP, University of Iowa

200 Hawkins Drive

Iowa City, IA 52242-1083 (USA)

Tel. +1 319356 3539, E-Mail thomas-scholz@uiowa.edu 
pregnant women with hyperglycemia [6], such that $5-8 \%$ of pregnancies in the USA and Europe and $15-20 \%$ in the developing world are complicated by diabetes [3].

Evidence that maternal hyperglycemia results in adult disease in the offspring was initially suggested by studies of the Pima Indians [7]. The Pima Indian population in Arizona has the highest prevalence of type II diabetes mellitus among children and adults $[8,9]$. Elegant epidemiologic studies by Dabelea et al. [1] demonstrated that the primary source of the increase in prevalence of diabetes among the children was being born to a mother with diabetes. The offspring of diabetic mothers also have an increased risk for obesity, hypertension and dyslipidemia $[9,10]$.

Animal models to study the developmental programming effects of in utero exposure to hyperglycemia have been described and have allowed long-term cardiovascular sequelae and their mechanisms to begin to be defined. Using rat models of severe maternal diabetes, investigators found that adult offspring of hyperglycemic mothers (OHM) have endothelial dysfunction of mesenteric arteries $[11,12]$. Our laboratory has recently developed a rat model of hyperglycemia during the last third of gestation [13]. Using this model, we found that animals in the neonatal period had a hypertrophic cardiomyopathy similar to that found in human offspring of diabetic mothers [14]. Importantly, the adult animals of the hyperglycemic mothers demonstrated gender-specific endothelial dysfunction and insulin resistance [13]. The goal of the current study was to further characterize cardiac function in adult offspring of late-gestation hyperglycemic mothers. We hypothesized that hearts from adult OHM would have cardiac dysfunction in vivo and be more susceptible to an ischemia-reperfusion insult.

\section{Materials and Methods}

\section{Rat Model of Late-Gestation Hyperglycemia}

Animal experiments were approved by the Institutional Animal Care and Use Committee of the University of Iowa and followed the Guide for the Care and Use of Laboratory Animals. The model of late-gestation maternal hyperglycemia has been described [13]. Briefly, timed pregnant Sprague-Dawley rats (Charles River Laboratories, Wilmington, Mass., USA) were injected with $50 \mathrm{mg} / \mathrm{kg}$ streptozotocin (STZ) intraperitoneally on day 12 of gestation. Serum glucose levels were monitored (LifeScan One Touch Ultra Blood Glucose Monitoring System, LifeScan Inc., Milpitas, Calif., USA) twice daily by sampling from tail-nicking. Insulin was given twice daily based on a sliding scale in order to maintain hyperglycemia between 200-400 mg/dl. Subcutaneous regular insulin (Humulin; Eli Lilly and Co., Indianapolis, Ind., USA) was given for the morning dose (1-3 units) and insulin-glargine (Lan- tus; Sanofi-Aventis, Bridgewater, N.J., USA) for the evening dose (1-3 units). Control pregnant rats were given the identical volume of citrate buffer without STZ, had serum glucose monitored twice daily and were given twice daily saline injections. Both OHM and control animals were allowed to deliver normally. All pups were cross-fostered to nondiabetic postpartum dams.

\section{Echocardiography}

In vivo echocardiography was performed by placing the rats in an induction chamber and achieving anesthesia with $2-3 \%$ isoflurane by a single investigator (B.E.R.), who was blinded as to whether the animals were from control or hyperglycemic mothers. After loss of the righting reflex, animals were placed on a warming platform and an appropriately sized nose cone was placed over the animal's nose. Anesthesia was maintained using $0.5-1 \%$ isoflurane. Temperature was monitored with a rectal thermometer and maintained between $35^{\circ} \mathrm{C}$ and $36^{\circ} \mathrm{C}$. Echocardiograms were performed using a Phillips Sonos 5500 with a $7.5-\mathrm{MHz}$ phased array transducer. Parasternal long axis, parasternal short axis, and apical four-chamber views were obtained in all animals. Pulsed wave Doppler recordings were made across the mitral valve when the Doppler sample volume was felt to be parallel to flow. Doppler tracings that were more than $20^{\circ}$ from parallel were not used for data analysis. M-mode recordings were obtained of the right and left ventricles in the parasternal short axis view at the level of the left ventricular papillary muscles. Measurements were made of Doppler waveforms across the mitral valve to obtain the $\mathrm{E}$ and $\mathrm{A}$ wave peak velocities from which the E/A ratio was then calculated. Measurements were made of the interventricular septum in diastole, left ventricular internal dimension in diastole, left ventricular internal dimension in systole, and left ventricular posterior wall in diastole. These measurements were then used to calculate the left ventricular fractional shortening. Calculations were made using software (Xcelera) incorporated in the ultrasound machine. Measurements were made in accordance with the American Society for Echocardiography Guidelines [15]. For the echo studies, the number of animals in each group was: male control $=6$, male $\mathrm{OHM}=9$, female control $=7$, and female $\mathrm{OHM}=7$.

\section{Langendorff Heart Preparation}

At 8-10 months of age, rats used for the echo studies and additional animals were weighed, heparinized intraperitoneally $(1,400 \mathrm{U} / \mathrm{kg})$ and anesthetized with inhaled isoflurane, and then given an intraperitoneal injection of ketamine $(50 \mathrm{mg} / \mathrm{kg}) / \mathrm{xyla}-$ zine $(5 \mathrm{mg} / \mathrm{kg})$. Hearts were rapidly removed and placed in icecold normal saline. The aorta was identified and cannulated and the coronaries perfused in the Langendorff mode at a constant pressure of $100 \mathrm{~cm}$ of water. In each case, retrograde perfusion of the hearts was established within $60 \mathrm{~s}$ following removal of the heart from the animal. The perfusion medium was KrebsHenseleit buffer composed of (in $\mathrm{mm}$ ) $111 \mathrm{NaCl}, 4.8 \mathrm{KCl}, 1.5$ $\mathrm{CaCl}_{2}, 1.2 \mathrm{MgSO}_{4}$, and $1.2 \mathrm{NaH}_{2} \mathrm{PO}_{4}, 1.2 \mathrm{NaHCO}_{3}, 5$ Glucose, 5 Lactate ( $\mathrm{pH} 7.4$ ) equilibrated with $95 \%$ oxygen $/ 5 \%$ carbon dioxide at $37^{\circ} \mathrm{C}$. A water-filled latex balloon was inserted into the left ventricle (LV) via an opening in the left atrium. Left ventricular pressure, heart rate and coronary perfusion rate were simultaneously recorded using a PowerLab 4/30 (ADInstruments Inc., Colorado Springs, Colo., USA) for later analysis.

The spontaneously beating heart was allowed to equilibrate for $15 \mathrm{~min}$ before initiating data collection for the baseline period. 
Table 1. Echocardiographic parameters measured on anesthetized animals

\begin{tabular}{llllllllll}
\hline & $\begin{array}{l}\text { IVSd } \\
\mathrm{mm}\end{array}$ & $\begin{array}{l}\text { PWd } \\
\mathrm{mm}\end{array}$ & $\begin{array}{l}\text { LVDd } \\
\mathrm{mm}\end{array}$ & $\begin{array}{l}\text { LVDs } \\
\mathrm{mm}\end{array}$ & $\begin{array}{l}\mathrm{FS} \\
\%\end{array}$ & $\begin{array}{l}\mathrm{E} \\
\mathrm{cm} / \mathrm{s}\end{array}$ & $\begin{array}{l}\mathrm{A} \\
\mathrm{cm} / \mathrm{s}\end{array}$ & $\begin{array}{l}\mathrm{E} / \mathrm{A} \\
\mathrm{HRm}\end{array}$ \\
\hline Male controls & $2.3 \pm 0.2$ & $2.2 \pm 0.2$ & $8.7 \pm 0.2$ & $5.2 \pm 0.4$ & $40.2 \pm 4.4$ & $87.4 \pm 6.2$ & $43.2 \pm 8.2$ & $2.36 \pm 0.56$ & $319 \pm 14$ \\
Male OHM & $2.2 \pm 0.1$ & $2.3 \pm 0.2$ & $8.1 \pm 0.3$ & $3.6 \pm 0.3^{*}$ & $54.8 \pm 2.9^{*}$ & $73.5 \pm 4.7$ & $73.8 \pm 7.3$ & $1.09 \pm 0.15^{*}$ & $321 \pm 12$ \\
Female controls & $1.7 \pm 0.1$ & $1.6 \pm 0.2^{\dagger}$ & $7.2 \pm 0.4^{*}$ & $3.9 \pm 0.3^{*}$ & $45.7 \pm 2.1$ & $83.4 \pm 5.2$ & $61.0 \pm 9.0$ & $1.53 \pm 0.27$ & $327 \pm 13$ \\
Female OHM & $2.1 \pm 0.2$ & $1.9 \pm 0.1$ & $6.6 \pm 0.5^{* \dagger}+$ & $3.0 \pm 0.2^{*}$ & $54.0 \pm 4.8$ & $89.8 \pm 6.3$ & $63.0 \pm 4.1$ & $1.45 \pm 0.11$ & $318 \pm 11$ \\
\hline
\end{tabular}

IVSd = Interventricular septum measure in diastole; PWd = posterior wall measured in diastole; FS = fractional shortening of the left ventricle; $\mathrm{HR}=$ heart rate during the echo procedure. ${ }^{*} \mathrm{p}<0.05$ vs. male controls; ${ }^{\dagger} \mathrm{p}<0.05$ vs. male OHM.

Table 2. Morphometric data from hearts following perfusion in the isolated working heart mode

\begin{tabular}{lllllllll}
\hline & $\mathrm{n}$ & $\begin{array}{l}\mathrm{HR} \\
\mathrm{bpm}\end{array}$ & $\begin{array}{l}\mathrm{BW} \\
\mathrm{g}\end{array}$ & $\begin{array}{l}\mathrm{HW} \\
\mathrm{g}\end{array}$ & $\begin{array}{l}\mathrm{HW} / \mathrm{BW} \\
\mathrm{g} / \mathrm{kg}\end{array}$ & $\begin{array}{l}\mathrm{LV} / \mathrm{BW} \\
\mathrm{g} / \mathrm{kg}\end{array}$ & $\begin{array}{l}\mathrm{RV} / \mathrm{BW} \\
\mathrm{g} / \mathrm{kg}\end{array}$ \\
\hline Male controls & 6 & $216 \pm 12$ & $697 \pm 69$ & $2.27 \pm 0.15$ & $3.37 \pm 0.31$ & $2.48 \pm 0.18$ & $0.59 \pm 0.03$ \\
Male OHM & 9 & $196 \pm 13$ & $797 \pm 24$ & $2.36 \pm 0.12$ & $2.95 \pm 0.10$ & $2.33 \pm 0.07$ & $0.48 \pm 0.03$ & $0.21 \pm 0.0 .01$ \\
Female controls & 9 & $197 \pm 11$ & $451 \pm 13^{*, \dagger}$ & $1.59 \pm 0.07^{*, \dagger}$ & $3.53 \pm 0.12$ & $2.53 \pm 0.10$ & $0.61 \pm 0.03$ & $0.25 \pm 0.02$ \\
Female OHM & 8 & $194 \pm 19$ & $426 \pm 29^{*, \dagger}$ & $1.65 \pm 0.08^{*, \dagger}$ & $4.01 \pm 0.18^{\dagger}$ & $2.85 \pm 0.16^{\dagger}$ & $0.70 \pm 0.05^{\dagger}$ & $0.24 \pm 0.01$ \\
\hline
\end{tabular}

$\mathrm{HR}=$ Heart rate; $\mathrm{BW}=$ body weight; $\mathrm{HW}=$ heart weight; $\mathrm{LV}=$ left ventricle; $\mathrm{RV}=$ right ventricle. ${ }^{*} \mathrm{p}<0.05$ vs. male controls; ${ }^{\dagger} \mathrm{p}<0.05$ vs. male OHM.

Hearts were then made ischemic by decreasing coronary flow to zero and maintained normothermic by placing them in a warmed buffer bath during the period of ischemia (normothermic ischemia). After $30 \mathrm{~min}$ of ischemia, coronary perfusion was restored and data collected at $1 \mathrm{~h}$ and $2.5 \mathrm{~h}$ after reperfusion. At each time point (baseline, $1 \mathrm{~h}$ after reperfusion, and $2.5 \mathrm{~h}$ after reperfusion), data were collected at three different preloads for 5 min with 5 min of equilibration between measurements. The left ventricular balloon volume was initially set at a $0-\mathrm{mm} \mathrm{Hg}$ preload and increased by $20 \mu \mathrm{l}$ for preload 2 and by an additional $20 \mu \mathrm{l}$ for preload 3. At the end of the experiment, the atria were excised from the hearts and the ventricles were weighed whole. The right ventricular free wall was removed and weighed, and the remaining LV including the septum was weighed. The number of animals in each group was: male control $=6$ (from 4 litters), male $\mathrm{OHM}=9$ (from 4 litters), female control $=9$ (from 3 litters), female $\mathrm{OHM}=8$ (from 5 litters).

Left ventricular pressure was monitored by the latex balloon in the LV attached to a pressure transducer. Left ventricular developed pressure was defined as the difference between the left ventricular systolic and diastolic pressures. Cardiac performance was assessed using the rate pressure product (RPP; heart rate $\times$ left ventricular developed pressure). Left ventricular compliance was calculated at baseline from the difference in balloon volume between preload 3 and preload $1(40 \mu \mathrm{l})$ divided by the difference in left ventricular diastolic pressure between preload 3 and preload 1 . Coronary flow was monitored from a flow transducer in line with the aortic cannula. Maximum and minimum change in pressure over time (max. $\mathrm{dP} / \mathrm{dT}$ and $\mathrm{min} . \mathrm{dP} / \mathrm{dT}$, respectively) were calculated utilizing the Chart5 software (ADInstruments Inc.).

\section{Statistics}

Data are expressed as means \pm standard error of the mean. Statistical evaluation for hemodynamic variables and morphometric variables was carried out by a two-tailed Student's t test or ANOVA. If ANOVA identified significant differences, pairwise comparisons were made using the Tukey test. $\mathrm{p}<0.05$ was defined as significant. Genders were analyzed separately.

\section{Results}

\section{Echocardiography}

Animals initially studied with echocardiography were allowed to recover for at least 3 days prior to undergoing heart perfusion experiments. Assessment of LV function in vivo was performed using echocardiography (table 1). All animals were sedated to a similar level of anesthesia based on heart rate. The dimension of the LV during systole (LVDs) was significantly greater in the male controls compared to the other groups. For the male control and OHM animals, a similar LV diastolic dimension (LVDd) was found. Therefore, a significant increase in the calcu- 
lated fractional shortening [(LVDd - LVDs)/LVDd] for the male OHM compared to male controls was observed, indicating enhanced systolic function in the male OHM hearts in vivo. Diastolic function of the $\mathrm{LV}$, as measured by the E/A ratio, was significantly decreased in male OHM compared to male controls (table 2). No differences in echocardiographic measurements between female $\mathrm{OHM}$ and female controls were found. When comparing differences between genders, the LV dimensions of the female hearts tended to be less than the males (consistent with their smaller size).

\section{Isolated Perfused Heart Studies}

Heart rate (during isolated heart perfusion) and morphometric parameters (obtained after perfusion) are summarized in table 2. There were no differences in heart rate across all groups. The differences between groups that were identified for the morphometric measures were found only between genders. The body weight and heart weight of control and OHM female rats were significantly less compared with both groups of male animals. Hearts from female OHM animals had a greater ratio of heart weight to body weight than the hearts from male OHM. Both the left ventricular/body weight and right ventricular/body weight ratios in the female OHM were increased compared to male OHM. The relative ratio of ventricular weight (left ventricular/right ventricular) was not different among any of the groups.

\section{$R P P$, Maximum $d P / d T$, Minimum $d P / d T$}

Starling effects due to greater myocyte stretch were readily assessed in the isolated perfused hearts. Increasing the preload in all four groups of hearts during the baseline perfusion was found to significantly increase the $\mathrm{RPP}$, maximum $\mathrm{dP} / \mathrm{dT}$ and minimum $\mathrm{dP} / \mathrm{dT}$, indicating that the hearts were well provided with substrates and responding appropriately to physiologic loads (fig. 1).

At baseline, male OHM hearts were found to have a significantly decreased RPP compared to male controls (fig. 1). Maximum $\mathrm{dP} / \mathrm{dT}$ and minimum $\mathrm{dP} / \mathrm{dT}$ were also significantly decreased compared to male controls when examined under preload 2 conditions (fig. 1).

After ischemia-reperfusion, there was a decrease in the function of the male control hearts that resulted in the male $\mathrm{OHM}$ and male controls no longer demonstrating a significant difference in their RPP, maximum $\mathrm{dP} / \mathrm{dT}$ or minimum $\mathrm{dP} / \mathrm{dT}$ at all preloads studied (fig. 2, $1 \mathrm{~h}$ after ischemia and $2.5 \mathrm{~h}$ after ischemia time points)

Female OHM had no difference in calculated RPP, maximum $\mathrm{dP} / \mathrm{dT}$ or minimum $\mathrm{dP} / \mathrm{dT}$ compared to fe-

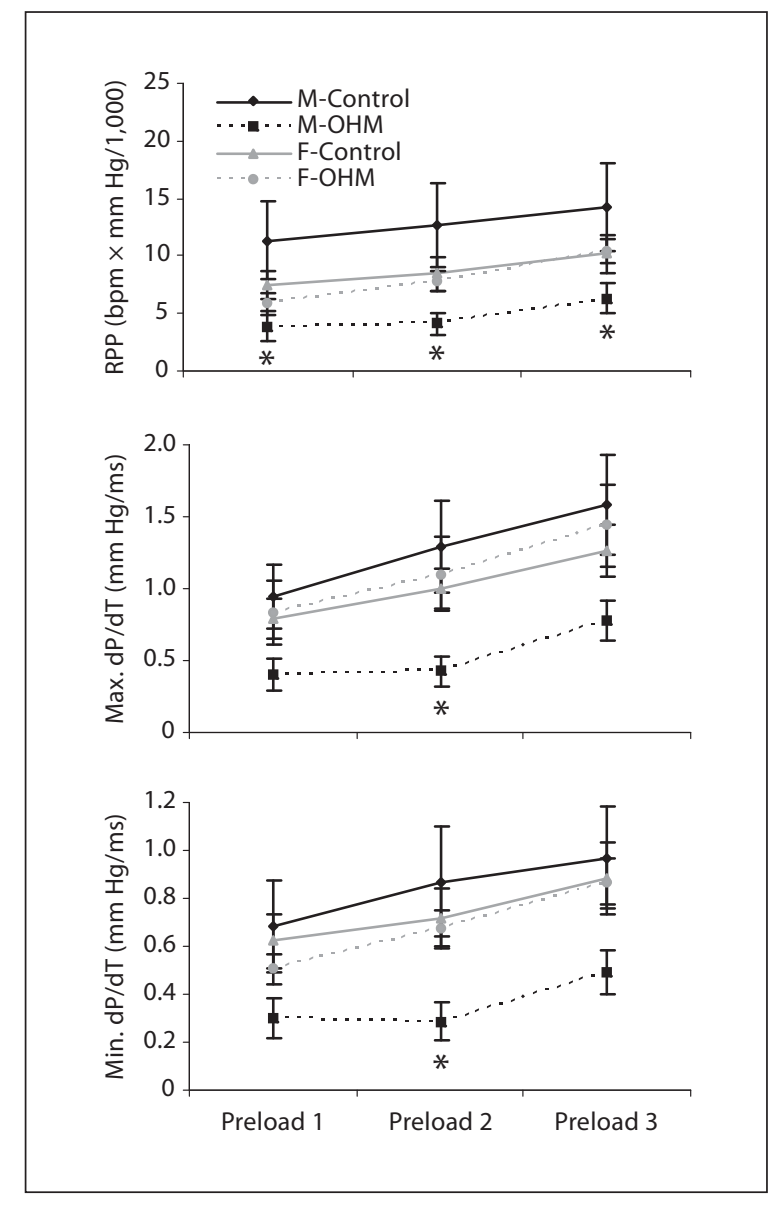

Fig. 1. Preload effects on ventricular function at baseline. RPP, and maximum positive and negative change in pressure as a function of time (max. $\mathrm{dP} / \mathrm{dT}$ and $\mathrm{min}$. $\mathrm{dP} / \mathrm{dT}$, respectively) were measured in isolated working hearts at three different preloads in the four groups of animals (male control, male OHM, female control, female OHM). ${ }^{*} \mathrm{p}<0.05$ for male OHM vs. male control.

male controls at baseline and after ischemia-reperfusion injury. Similar to male controls, both female controls and female OHM demonstrated a significant decline in function at 1 and $2.5 \mathrm{~h}$ after ischemia (fig. 2).

\section{Cardiac Compliance}

At baseline, the compliance of the LV of the male $\mathrm{OHM}$ hearts was significantly decreased compared to male control hearts, suggesting increased stiffness of the $\mathrm{LV}$ in the OHM hearts (fig. 3). The compliance of the ventricle was $0.21 \pm 0.01 \mu \mathrm{l} / \mathrm{mm} \mathrm{Hg}$ in male OHM versus $0.27 \pm 0.02 \mu \mathrm{l} / \mathrm{mm} \mathrm{Hg}$ in male control animals. This reflects a significantly greater change in left ventricular pressure with male OHM hearts compared to male con- 


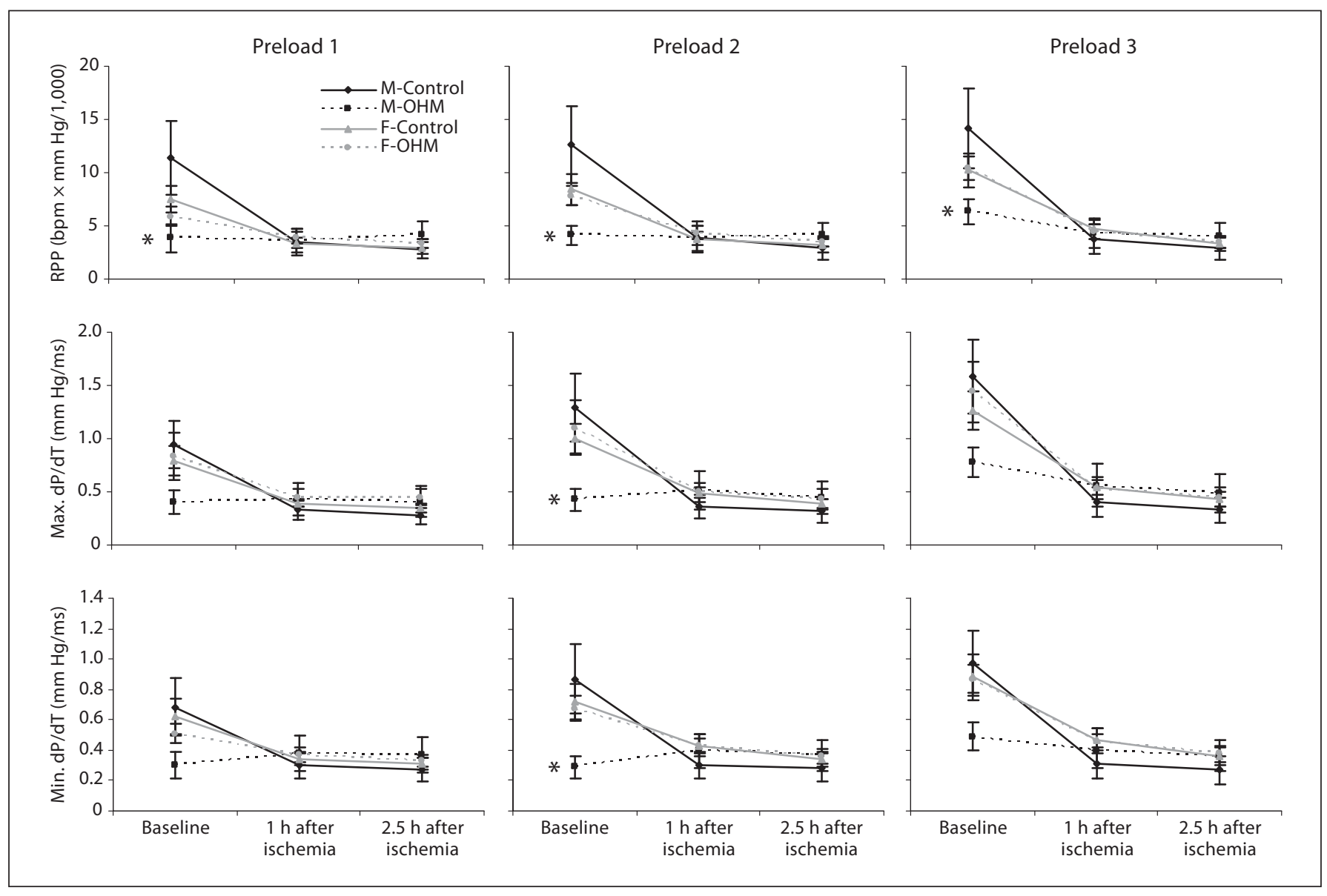

Fig. 2. Ventricular function following an ischemic insult. Isolated working hearts were subjected to a 30-min ischemic insult followed by reperfusion. Functional measurements including the RPP and maximum positive and negative change in pressure as a function of time (max. $\mathrm{dP} / \mathrm{dT}$ and $\mathrm{min} . \mathrm{dP} / \mathrm{dT}$, respectively) were measured at $1 \mathrm{~h}$ and $2.5 \mathrm{~h}$ after reperfusion at three different preloads. Measurements were made in four groups of animals (male control, male OHM, female control, female OHM). ${ }^{*} \mathrm{p}<0.05$ for male OHM vs. male control.

trols for a given change in left ventricular preload. The difference in compliance between female OHM and female controls did not reach significance $(0.21 \pm 0.02$ versus $0.26 \pm 0.02 \mu \mathrm{l} / \mathrm{mm} \mathrm{Hg}$, respectively).

\section{Discussion}

This study demonstrated that exposure to a hyperglycemic in utero environment results in changes in cardiac function that persist into adulthood. Specifically, we found that compared to male controls, adult male $\mathrm{OHM}$ had diminished left ventricular diastolic function in vivo and in the perfused heart along with an increased sensitivity to a brief ischemia-reperfusion insult (the time from heart excision to cannulation on Langendorff).

The alterations in cardiac function in the adult male OHM are similar to those found in the neonatal period in human offspring of diabetic mothers. In human newborns, OHM were found to have echocardiographic evidence of diastolic dysfunction compared to normal neonates $[16,17]$. No study, to our knowledge, has followed these offspring into adulthood to determine if the diastolic dysfunction persists. In addition, we observed that the male OHM had an increased shortening fraction compared to control male offspring despite similar heart rates during echocardiographic imaging. The increased shortening fraction was the result of a decreased left ventricular end systolic volume, suggesting that the cardiac 


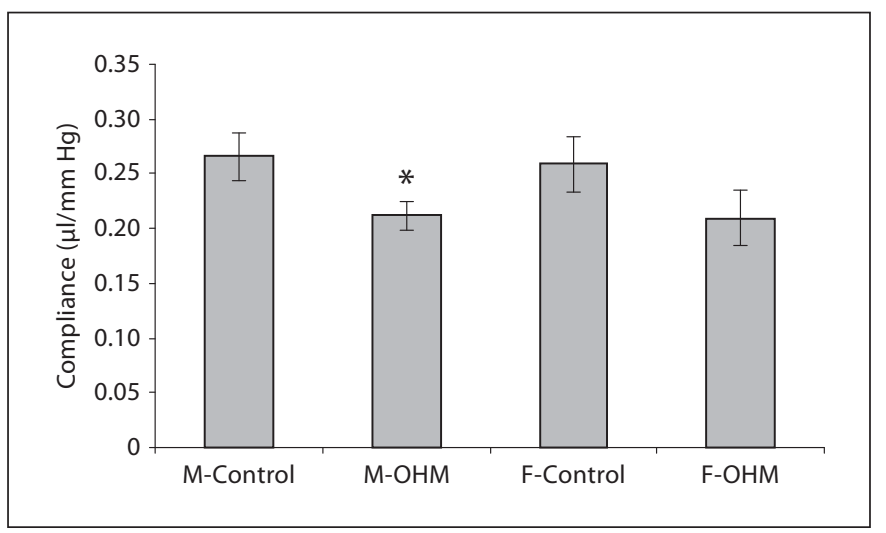

Fig. 3. Left ventricular compliance in the isolated, working hearts at baseline. Ventricular compliance of male control, male OHM, female control and female OHM were determined as described in 'Materials and Methods'. * $\mathrm{p}<0.05$ for male OHM vs. male control.

contractility of the male OHM hearts was increased in vivo. This may reflect altered sensitivity to neurohormonal factors that directly impact contractility, such as calcium cycling, which would be independent of chronotropic effects on the heart.

Despite enhanced systolic function in vivo, the male $\mathrm{OHM}$ demonstrated diminished function during baseline measurements in the isolated, perfused hearts. A possible explanation for this finding is that an enhanced adrenergic drive existed in vivo or some other neurohumoral factors were present in the intact animal. As mentioned above, this could account for the increased systolic function measured by echocardiography. Upon removal of the heart for the Langerdorff preparation, these in vivo influences would have been removed, resulting in decreased function in the isolated heart at baseline.

An alternative explanation may be that the hearts from the male OHM have an enhanced susceptibility to the brief ischemia-reperfusion insult that occurred when establishing the perfused heart. As described in the 'Methods' section, the time interval from heart removal from the animals to coronary reperfusion with oxygenated media was always less then $60 \mathrm{~s}$ and the hearts were maintained in ice-cold saline during identification and dissection of the ascending aorta. To our knowledge, differences in baseline function of isolated perfused hearts are not typically observed between study groups.

However, it is interesting to note that while both groups of control animals and female OHM hearts demonstrated significant declines in function following the 30-min ischemic insult, the male $\mathrm{OHM}$ did not. The preservation of function following global ischemia in the male OHM indicates that some mechanism of cardioprotection existed in these animals. This finding may suggest some degree of preconditioning developed in the adult $\mathrm{OHM}$ hearts during the brief ischemia-reperfusion period during the establishment of coronary perfusion. Alternatively, some inherent metabolic or structural protein alterations may exist in male OHM hearts that result in their resistance to an ischemic insult, similar to what is found in neonatal hearts [18].

While the mechanisms that may lead to increased susceptibility to a brief ischemia-reperfusion insult in the adult male OHM are unknown, they may be related to greater oxidative stress or sensitivity to oxidative stress. Previous studies utilizing the STZ rat model of gestational diabetes have shown that maternal and fetal blood levels of 8-isoprostaglandin $\mathrm{F}_{2 \mathrm{alpha}}$, a sensitive marker for lipid peroxidation, are significantly increased above control levels [19]. Enhanced susceptibility to oxidative stress in adult offspring programmed by exposure to an adverse intrauterine environment has been demonstrated using a maternal low-protein diet method of intrauterine stress [20, 21]. Elmes et al. [20] found impaired recovery of left ventricular developed pressure after an ischemia-reperfusion injury. Pretreatment of the adult rats with $\mathrm{N}$-acetylcysteine improved recovery following the ischemic injury [21]. $\mathrm{N}$-acetylcysteine enhances the antioxidant capacity of the heart by increasing glutathione production, which is then available to react with, and detoxify, endogenously produced hydrogen peroxide. Thus, improvement of cardiac function with supplemental $\mathrm{N}$-acetylcysteine suggested that enhancing the intrinsic antioxidant status of the cardiac tissues could attenuate the greater ischemia-reperfusion injury in the programmed hearts [21].

Abnormal systolic and diastolic cardiac function were seen only in the male OHM. The gender differences found in this study were not unexpected and have been observed in other models of developmental programming [22-24]. In the majority of cases of gender susceptibility following exposure to an adverse intrauterine environment, male offspring are found to be more affected by the adverse fetal environment than female offspring. This has been found in animal models of maternal dietary restrictions, steroid exposure and hypoxia [25]. While it has been speculated that these differences are due to estrogen or testosterone exposure, no studies to date have specifically defined the basis of the gender differences found in developmental programming models. Unfortunately, in most studies of human offspring of di- 
abetic mothers, cardiac findings are generally not divided by gender. Gender differences are critical to consider as further investigation into the developmental origins of disease occurs. Patient surveillance and treatment may require gender-based considerations if these findings are replicated in human studies.

An important limitation when comparing the results using the late-gestation hyperglycemia model described in this study with human studies of gestational diabetes is that STZ-induced hyperglycemia is due to maternal insulin deficiency rather than maternal insulin insensitivity. There is a wealth of human literature comparing the outcomes of pregnancies from type 1, type 2 and gestational diabetic mothers (see review by Weindling [26]). Despite varying states of maternal insulinemia with the differing types of diabetes, it appears that the level of glucose control determines the impact on the neonate. As long as maternal glucose control is similar, the perinatal outcomes are very comparable in these three conditions, including similar rates of macrosomia, hyperglycemia and need for intensive care. However, the developmental programming effects of maternal hyperglycemia on car- diovascular function have not been extensively studied in humans in the various states of maternal insulinemia and further studies are needed.

Data are beginning to demonstrate that children of diabetic mothers are at higher risk for adverse cardiovascular events later in life, although the number of studies is limited [27-29]. The extent to which maternal hyperglycemia produces an adverse intrauterine environment that can program adult disease is not known, although it is clear that such a link exists $[3,30]$. To our knowledge, this is the first study to indicate that myocardial dysfunction occurs in vivo in the adult OHM. Given the rapidly increasing prevalence of type 2 diabetes during the childbearing years [31], it is anticipated that the number of adults exposed to hyperglycemia in utero will continue to increase, making the identification and characterization of long-term cardiovascular complications a priority.

\section{Disclosure Statement}

Statement of financial support: research supported by T32HL-07413 to M.A. and R01-HL-088883 to T.D.S.

\section{References}

-1 Dabelea D, Hanson RL, Bennett PH, Roumain J, Knowler WC, Pettitt DJ: Increasing prevalence of type II diabetes in American Indian children. Diabetologia 1998;41:904910.

-2 Metzger BE, Lowe LP, Dyer AR, Trimble ER, Chaovarindr U, Coustan DR, Hadden DR, McCance DR, Hod M, McIntyre HD, Oats JJ, Persson B, Rogers MS, Sacks DA: Hyperglycemia and adverse pregnancy outcomes. N Engl J Med 2008;358:1991-2002.

-3 Simeoni U, Barker DJ: Offspring of diabetic pregnancy: long-term outcomes. Semin Fetal Neonatal Med 2009;14:119-124.

-4 Barker DJ, Osmond C, Golding J, Kuh D, Wadsworth ME: Growth in utero, blood pressure in childhood and adult life, and mortality from cardiovascular disease. BMJ 1989;298:564-567.

$\checkmark 5$ Barker DJ, Winter PD, Osmond C, Margetts B, Simmonds SJ: Weight in infancy and death from ischaemic heart disease. Lancet 1989;2:577-580.

-6 Dabelea D, Snell-Bergeon JK, Hartsfield CL, Bischoff KJ, Hamman RF, McDuffie RS: Increasing prevalence of gestational diabetes mellitus (GDM) over time and by birth cohort: Kaiser Permanente of Colorado GDM screening program. Diabetes Care 2005;28: 579-584.
-7 Pettitt DJ, Baird HR, Aleck KA, Bennett PH, Knowler WC: Excessive obesity in offspring of Pima Indian women with diabetes during pregnancy. N Engl J Med 1983;308:242-245.

-8 Franks PW, Looker HC, Kobes S, Touger L, Tataranni PA, Hanson RL, Knowler WC: Gestational glucose tolerance and risk of type 2 diabetes in young Pima Indian offspring. Diabetes 2006;55:460-465.

-9 Pettitt DJ, Nelson RG, Saad MF, Bennett PH, Knowler WC: Diabetes and obesity in the offspring of Pima Indian women with diabetes during pregnancy. Diabetes Care 1993;16: 310-314

10 Manderson JG, Mullan B, Patterson CC Hadden DR, Traub AI, McCance DR: Cardiovascular and metabolic abnormalities in the offspring of diabetic pregnancy. Diabetologia 2002;45:991-996.

$\checkmark 11$ Holemans K, Gerber RT, Meurrens K, De Clerck F, Poston L, Van Assche FA: Streptozotocin diabetes in the pregnant rat induces cardiovascular dysfunction in adult offspring. Diabetologia 1999;42:81-89.

2 Rocha SO, Gomes GN, Forti AL, do Carmo Pinho Franco M, Fortes ZB, de Fatima Cavanal M, Gil FZ: Long-term effects of maternal diabetes on vascular reactivity and renal function in rat male offspring. Pediatr Res 2005;58:1274-1279.
13 Segar EM, Norris AW, Yao JR, Hu S, Koppenhafer SL, Roghair RD, Segar JL, Scholz TD: Programming of growth, insulin resistance and vascular dysfunction in offspring of late gestation diabetic rats. Clin Sci (Lond) 2009; 117:129-138.

14 Reinking BE, Wedemeyer EW, Weiss RM, Segar JL, Scholz TD: Cardiomyopathy in offspring of diabetic rats is associated with activation of the MAPK and apoptotic pathways. Cardiovasc Diabetol 2009;8:43

15 Lang RM, Bierig M, Devereux RB, Flachskampf FA, Foster E, Pellikka PA, Picard MH, Roman MJ, Seward J, Shanewise JS, Solomon SD, Spencer KT, Sutton MS, Stewart WJ: Recommendations for chamber quantification: a report from the American Society of Echocardiography's Guidelines and Standards Committee and the Chamber Quantification Writing Group, developed in conjunction with the European Association of Echocardiography, a branch of the European Society of Cardiology. J Am Soc Echocardiogr 2005;18:1440-1463.

16 Demiroren K, Cam L, Oran B, Koc H, Baspinar O, Baysal T, Karaaslan S: Echocardiographic measurements in infants of diabetic mothers and macrosomic infants of nondiabetic mothers. J Perinat Med 2005;33:232235 . 
-17 Kozak-Barany A, Jokinen E, Kero P, Tuominen J, Ronnemaa T, Valimaki I: Impaired left ventricular diastolic function in newborn infants of mothers with pregestational or gestational diabetes with good glycemic control. Early Hum Dev 2004;77:13-22.

18 Jonas RA: Myocardial protection for neonates and infants. Thorac Cardiovasc Surg 1998;46(suppl 2):288-291.

-19 Gerber RT, Holemans K, O’Brien-Coker I, Mallet AI, van Bree R, Van Assche FA, Poston L: Increase of the isoprostane 8-isoprostaglandin $\mathrm{F}_{2 \text { alpha }}$ in maternal and fetal blood of rats with streptozotocin-induced diabetes: evidence of lipid peroxidation. Am J Obstet Gynecol 2000;183:1035-1040.

-20 Elmes MJ, Gardner DS, Langley-Evans SC: Fetal exposure to a maternal low-protein diet is associated with altered left ventricular pressure response to ischaemia-reperfusion injury. Br J Nutr 2007;98:93-100.

-21 Elmes MJ, McMullen S, Gardner DS, Langley-Evans SC: Prenatal diet determines susceptibility to cardiac ischaemia-reperfusion injury following treatment with diethylmaleic acid and N-acetylcysteine. Life Sci 2008; 82:149-155.
22 Bellinger L, Langley-Evans SC: Fetal programming of appetite by exposure to a maternal low-protein diet in the rat. Clin Sci (Lond) 2005;109:413-420.

23 Gilbert JS, Ford SP, Lang AL, Pahl LR, Drumhiller MC, Babcock SA, Nathanielsz PW, Nijland MJ: Nutrient restriction impairs nephrogenesis in a gender-specific manner in the ovine fetus. Pediatr Res 2007;61:42-47.

24 von Bergen NH, Koppenhafer SL, Spitz DR, Volk KA, Patel SS, Roghair RD, Lamb FS, Segar JL, Scholz TD: Fetal programming alters reactive oxygen species production in sheep cardiac mitochondria. Clin Sci (Lond) 2009;116:659-668.

25 Grigore D, Ojeda NB, Alexander BT: Sex differences in the fetal programming of hypertension. Gend Med 2008;5(suppl A):S121S132.

26 Weindling AM: Offspring of diabetic preg nancy: short-term outcomes. Semin Fetal Neonatal Med 2009;14:111-118.
27 Dabelea D: The predisposition to obesity and diabetes in offspring of diabetic mothers. Diabetes Care 2007;30(suppl 2):S169-S174.

28 Lee H, Jang HC, Park HK, Cho NH: Early manifestation of cardiovascular disease risk factors in offspring of mothers with previous history of gestational diabetes mellitus. Diabetes Res Clin Pract 2007;78:238-245.

29 Vohr BR, Boney CM: Gestational diabetes: the forerunner for the development of maternal and childhood obesity and metabolic syndrome? J Matern Fetal Neonatal Med 2008;21:149-157.

30 Segar EM, Norris AW, Yao JR, Hu S, Koppehnafer SL, Roghair RD, Segar JL, Scholz TD: Programming of growth, insulin resistance and vascular dysfunction in offspring of late gestation diabetic rats. Clin Sci (Lond) 2009.

31 Kaufman FR: Type 2 diabetes mellitus in children and youth: a new epidemic. J Pediatr Endocrinol Metab 2002;15(suppl 2):737744 . 